\title{
Aspectos da crítica sobre jovens artistas nas páginas do Jornal do Brasil (1950-2000)
}

\author{
Guilherme Marcondes dos Santos ${ }^{1}$
}

\section{Resumo}

O objetivo deste artigo é compreender como jovens artistas / artistas emergentes / artistas em início de carreira foram sendo representados/as/xs nas críticas de arte veiculadas pelo Jornal do Brasil (JB) na segunda metade do século XX. Pergunta-se porque o jornal destinou tantos recursos e espaço nas suas páginas para tratar de jovens artistas ainda desconhecidos e em processo de legitimação pelo circuito de arte? E, ainda, quais foram os valores acionados para reconhecer e até mesmo consagrar alguns artistas e excluir outros? Essas são algumas das perguntas que levaram ao estudo de três casos típicos da crítica no período analisado, aqui caracterizados como: arte com estirpe; arte com personalidade e magia; e o mercado de arte e a arte jovem. A escolha do JB se deu pela sua importância para a circulação da crítica de arte e legitimação de carreiras artísticas naquela época. O texto utiliza pesquisa realizada na Hemeroteca Digital da Biblioteca Nacional, no Rio de Janeiro, que resultou na escolha de matérias consideradas expressivas dos modos de representação dos jovens artistas visuais/ plásticos/as/xs ao longo de seis décadas.

Palavras-chaves: Jornal do Brasil; crítica de arte; jovens artistas; legitimação; sociologia da arte.

Aspects of the criticism about young artists in the pages of Jornal do Brasil (1950-2000)

\section{Abstract}

The aim of this article is to understand how young artists / emerging artists / early artists were represented in the art criticisms published by Jornal do Brasil (JB) in the second half of the 20th century. Asking why the newspaper has allocated so much resources and space in its pages to deal with young artists still unknown and in process of legitimation by the art circuit? And, what were the values applied to recognize and even consecrate some artists and exclude others? These are some of the questions that led to the study of three typical cases of criticism in the analyzed period, characterized here as: art with strain; art with personality and magic; and the art market and young art. The choice of JB was due to its importance for the circulation of art criticism and legitimation of artistic careers at that time. The text uses a research carried out in the Hemeroteca Digital of Biblioteca Nacional Library, in Rio de Janeiro, which resulted in the choice of subjects considered expressive of the modes of representation of the young visual/plastic artists during six decades.

Keywords: Jornal do Brasil; art criticism; young artists; legitimation; sociology of art.

1 Pós-doutorando (com bolsa PNPD/CAPES) no Programa de Pós-Graduação em Sociologia da Universidade Estadual do Ceará (UECE). Doutor e mestre pelo Programa de Pós-Graduação em Sociologia e Antropologia da UFRJ. 


\section{Introdução ${ }^{2}$}

A crítica de arte não é novidade. Suas origens remontam ao século XVIII quando críticos $^{3}$ literários escreviam sobre arte. A crítica de caráter generalista, segundo Terry Eagleton (1991) foi dando lugar à especialização e profissionalização, processo que atingiu o seu auge em meados no século XX. Com o surgimento de especialistas, critérios mais rígidos e técnicos passaram a ser usados para a avalição e julgamento dos trabalhos de arte. O papel do crítico de arte ganhou visibilidade e importância no sistema artístico, contribuindo para a criação de um novo léxico e o fortalecimento do processo de legitimação de artistas e instituições. Os críticos de arte foram então reconhecidos como autoridades com prerrogativas especais para o exercício judicativo no campo da arte, nas palavras de Pierre Bourdieu (1996; 2011), ou um mundo da arte, nos termos de Howard Becker (2008).

O espaço concedido aos críticos nas páginas dos jornais foi crucial para o florescimento da crítica de arte. Desde a segunda metade do século XVIII, a imprensa foi a condição sem a qual aqueles profissionais não teriam podido intermediar a relação entre artistas e o público, atuando como tradutores das questões artísticas $^{4}$ e fazendo circular suas ideias sobre a arte $^{5}$. Os críticos de arte se tornaram atores imprescindíveis para a circulação de nomes de artistas e conhecimentos sobre suas obras. Com a profissionalização começaram a trabalhar no limite entre a arte e a ciência, buscando entender a chamada liberdade artística ${ }^{6}$ a partir de conceitos das mais diversas áreas do saber.

A legitimação de artistas e suas práticas ficou em larga escala na dependência do juízo positivo ou negativo da crítica que veiculavam sobre artistas jovens ou reconhecidos(as/xs) e consagrados(as/xs). Figurar positivamente no texto de $\operatorname{um}(\mathrm{a} / \mathrm{x})$ crítico $(\mathrm{a} / \mathrm{x})$ de arte com destaque na imprensa poderia ser o trampolim para a legitimação de artistas iniciantes / artistas emergentes / jovens artistas, bem como fundamental para a manutenção de carreiras artísticas já estabelecidas. Ao mesmo tempo, figurar negativamente na crítica feita por um $(\mathrm{a} / \mathrm{x})$ profissional da crítica de arte poderia contribuir para arruinar uma carreira. Destarte, nos anos de 1950 e 1960, os(as/xs) críticos(as/ xs) de arte passaram a ter papel determinante para a definição dos caminhos a serem seguidos no universo das artes visuais (OGUIBE, 2004, p. 15) e na legitimação de artistas (MARCONDES, 2014).

\section{Caminhos da crítica de arte}

No contexto brasileiro, o crítico de arte e

2 Este artigo apresenta algumas questões discutidas em minha tese de doutorado Arte e Consagração: Os Jovens Artistas da Arte Contemporânea, defendida em maio de 2018, no Programa de Pós-Graduação em Sociologia e Antropologia da UFRJ. A escolha dos textos analisados neste artigo foi feita a partir de levantamento e estudo dos exemplares do JB depositados na Hemeroteca Digital da Biblioteca Nacional, começando pela combinação das palavras "jovem" e "artista", que indicou mais de 1000 matérias sobre o assunto.

3 Opta-se aqui por não utilizar uma marcação de gênero inclusiva de mulheres e indivíduos não-binários pois, ao que se sabe, os primeiros críticos de arte que contribuíram para a profissionalização da crítica eram homens que se auto identificavam de acordo com seu gênero de nascimento. Mas a marcação de gênero mais inclusiva é utilizada em outras partes do texto, afinal, após seu surgimento e profissionalização também se contou, por exemplo, com a atuação de mulheres fazendo crítica de arte profissionalmente.

4 Em O Público de Arte e o Crítico (1975), o curador, crítico de arte e historiador da arte Henry Geldzahler, diz que: "Foi apenas quando houve um falso passo para a democratização da arte, no século XIX, que o crítico profissional tornouse necessário, como uma espécie de amortecedor, colocado entre o pintor e o público. Estabeleceu-se assim uma nova profissão, a de intérprete de arte para o grande público". (GELDZAHLER, 1975:76).

5 Vale lembrar que esta circulação se limitava ao público alfabetizado, que no caso brasileiro, em meados do século XX, não dizia respeito a maioria de sua população, que comprava e lia jornais.

6 Uma liberdade que pode ser compreendida como relativa, já que se dava no século XX como anteriormente, e mesmo atualmente, a partir de regras pré-estabelecidas na interação entre os diferentes atores profissionais da arte e as instituições artísticas. Com isso busca-se argumentar que apesar da ideia de liberdade permear a produção artística, estão sujeitas às regras de funcionamento do sistema artístico. 
militante de esquerda, Mário Pedrosa (19001981) é considerado uma figura modelar. Sua atuação no campo da arte e, especialmente, sua crítica veiculada em colunas de jornais é apontada como um alvo a ser perseguido. De sua atuação, em meados do século XX, merece destaque sua aproximação com o grupo de artistas concretistas e neoconcretistas da cidade do Rio de Janeiro, com os quais o crítico estabeleceu vínculos fortes e sobre os quais escreveu em favor de sua legitimação. Desta forma foi se inserindo ele próprio como crítico de arte na história da arte brasileira. Artistas como Abraham Palatnik (1928-), Almir Mavignier (1925-2018), Hélio Oiticica (1937-1980), Ivan Serpa (1923-1973), Lygia Clark (1920-1988) e Lygia Pape (19272004) se tornaram cânones da arte brasileira, tendo Pedrosa incentivado e defendido as linguagens artísticas inovadoras que marcaram seus trabalhos.

Todavia, mudanças radicais alteraram as estruturas e regras do sistema artístico com o advento da arte contemporânea, na década de 1960; uma transformação progressiva e conectada com alterações ocorridas em outros âmbitos da sociedade, sobretudo, o surgimento da internet, que implicou em modificações substanciais envolvendo indivíduos e sociedades global e localmente (CASTELLS, 1999). Além disso, a arte contemporânea como um novo paradigma alterou os modos de conceber, produzir, receber e comercializar os trabalhos artísticos, destituindo as obras de seu caráter objetual e deslocando o lugar de importância da crítica veiculada pelos jornais (ver: HEINICH, 2014). Tais mudanças acarretaram a emergência de um novo sistema de regras e novos profissionais das artes passaram a ser solicitados a fim de integrar uma estrutura condizente com as regras da arte contemporânea. No bojo destas transformações surgiram os(as/xs) curadores(as/xs) responsáveis pela concepção e realização de exposições, que vem se destacando cada vez mais no campo artístico pelo desempenho do papel de reconhecer e legitimar artistas e instituições.

Em Transformação: A Crítica de Arte Visuais nos Jornais Cariocas nos Anos 90 (2008), Mauro
Trindade revela o arrefecimento da crítica de arte nos jornais cariocas nos anos de 1990, situação similar a que percebia em outros contextos dentro efora do Brasil. Esta transformação, que se deu em virtude de novas demandas do mercado editorial, alterou o espaço e o teor das críticas de arte nos periódicos. Em substituição ao que Trindade chama de uma crítica de arte militante, surgiu o chamado jornalismo cultural, modificando uma das principais, se não a principal prerrogativa da crítica de arte, de intermediar as relações entre a arte e o público. Trindade argumenta que o jornalismo cultural seria "[...] o segmento do jornalismo responsável pela cobertura da produção e da circulação de bens culturais na sociedade" e cuidaria "[...] das reportagens sobre teatro, cinema, literatura, música, dança, artes visuais, gastronomia, televisão, ciências humanas e assuntos referentes aos órgãos e instituições que atuam nesses campos. Ainda transborda para moda, arquitetura, automóveis e comportamento, conforme o enfoque das reportagens específicas" (TRINDADE, 2008, p. 29). É possível dizer, então, que o mencionado jornalismo cultural é parte de uma rede de institucionalização da arte, no entanto, seu teor se distingue da chamada crítica de arte militante, própria do período auge da profissionalização da crítica de arte e praticada, para citar o caso brasileiro, por críticos como Mário Pedrosa e Ferreira Gullar (1930-2016). Através de seus textos críticos publicados nos jornais, estes críticos profissionais não apenas divulgavam uma agenda cultural ou anunciavam fatos ocorridos no âmbito da produção artística, seus trabalhos reuniam uma gama de conceitos e saiam em defesa de artistas, linguagens estéticas e instituições. Eram, neste sentido, partidários e informativos. E, os textos vinculados ao jornalismo cultural, podem ser compreendidos como mais informativos que partidários ${ }^{7}$.

Em Arte, Crítica e Curadoria: Diálogos sobre Autoridade e Legitimidade (MARCONDES, 2014) analiso o debate contemporâneo que apregoa o fim da crítica como atividade profissional de relevância para a legitimação de artistas e instituições em detrimento da curadoria de exposições. Ao longo do trabalho 
foi possível perceber que enquanto os(as/xs) curadores(as/xs) de exposições passaram a ser vistos(as/xs) como estrelas do mundo da arte em detrimento dos artistas (AMARAL, 2006) também deslocaram os(as/xs) críticos(as/xs) de arte de seu lugar privilegiado. A pesquisa mostrou que profissionais das artes visuais passaram a ter uma atuação múltipla. Neste sentido, é cada vez mais comum que curadores(as/xs) atuem como críticos(as/xs) e/ou professores(as/xs) ou que artistas sejam curadores e, também, por vezes professores(as/xs).

\section{A crítica de arte na segunda metade do} século XX: casos típicos

\section{Considerando as mudanças ocorridas} no campo da crítica, este artigo empreende um retorno ao período em que a crítica de arte era por excelência uma das atividades legitimadoras do campo artístico, com o objetivo de compreender como os(as/xs) jovens artistas ${ }^{9}$ eram retratados. Afinal, a crítica de arte teve um papel consagratório de relevância e este retorno histórico pode contribuir para a análise dos processos de transformação do sistema artístico.
Interessa saber como se faziam reconhecer como artistas profissionais, através das palavras dos(as/ xs) críticos(as/xs) de arte, aqueles(as/xs) até então "desconhecidos" do circuito artístico. Além disso, busca-se averiguar o porquê de críticos(as/ xs) consagrados(as/xs), que possuíam espaço nas disputadas páginas dos jornais, se ocupavam da produção estética dos jovens. Minha hipótese é de que havia (e ainda existe) um interesse institucional pela novidade (MARCONDES, 2018), que se define pela renovação de gerações de artistas ao longo do tempo a partir de uma busca constante pela novidade da criação artística que se crê estar na prática e criatividade dos jovens ${ }^{10}$.

A seguir aponto algumas características da crítica de arte na segunda metade do século XX no Jornal do Brasill ${ }^{11}$, que por ter sido um dos principais veículos da crítica de arte do país, pode elucidar as questões postas por este trabalho.

\section{1 - Arte com Estirpe}

Em diversas matérias publicadas no Jornal do Brasil percebe-se que seus autores mostravam ao público as qualidades de $\mathrm{um}(\mathrm{a} / \mathrm{x})$ artista jovem. Recorriam, por vezes: 1) ao currículo dos(as/xs)

7 Cabe destacar, portanto, o papel de Pedrosa, especialmente, no processo de legitimação dos(as) chamados(as) artistas concretistas da cidade do Rio de Janeiro, e o de Gullar na legitimação dos(as) artistas neoconcretistas. Suas contribuições não se deram apenas através da divulgação de exposições, mas dos textos que publicavam acerca destes(as) artistas e em apoio às linguagens estéticas que fundavam. Ferreira Gullar, inclusive, atuou na redação do Manifesto Neocontreto, publicado em março de 1959 no Suplemento Dominical do Jornal do Brasil, ao lado dos(as) artistas que buscavam romper com as linguagens artísticas até então vigentes. Já Pedrosa protagonizou uma peleja nos jornais com Quirino Campofiorito (1902-1993) acerca da produção de artistas considerados loucos, pois ao primeiro tais produções poderiam ser consideradas detentoras de um caráter artístico legítimo para o campo da arte, e ao segundo esta produção não deveria ser assim considerada pois faltaria uma intencionalidade artística por parte de seus produtores (VILLAS BÔAS, 2008). Estes críticos podem ser, desta forma, encarados como responsáveis por textos críticos de caráter militante, pois levavam à esfera pública os debates em torno às questões próprias do mundo da arte tomando posicionamentos partidários sobre artistas, linguagens estéticas, conceitos e instituições.

8 A crítica de arte, curadora e professora Aracy Amaral, apresentou, em 1988, no Museu de Arte Moderna de Nova York o texto O Curador como Estrela (2006), trabalho em que a autora trata da ascensão da curadoria. Para Amaral: “(...) assim como vivemos uma época de cinema de diretores - e não cinema de histórias e autores -, nas artes visuais também vivemos, ao que parece, um tempo de exposições de curadores, e não mais de artistas. Os grandes personagens do meio artístico internacional parecem ser, de fato, os curadores. Parece importar, portanto, menos a obra de arte em si, e o artista que se coloca como seu autor, mas a manipulação dos movimentos artísticos pelos curadores que produzem esses eventos milionários que provocam filas diante de museus, centros culturais, Bienais ou Documentas". (AMARAL, 2006, p. 51).

9 Jovem artista é uma categoria construída a partir de pesquisa realizada para a tese (MARCONDES, 2018), sobre o processo de legitimação dos denominados jovens artistas / artistas emergentes / artistas em início de carreira. Estas categorizações são tomadas como sinônimas e entrecruzam idade e tempo de carreira dos(as/xs) artistas em processo de construção de carreira, em busca de visibilidade e legitimidade.

10 Consultar capítulo 8 da tese Arte e Consagração: Os Jovens Artistas da Arte Contemporânea (MARCONDES, 2018). 
artistas, destacando o nome de seus professores; 2) vinculavam tais artistas à historiografia da arte, conectando sua produção a artistas considerados como "grandes mestres"; 3) recorriam também à opinião de outros profissionais das artes visuais/plásticas para corroborar seus próprios comentários; e, 4) finalmente apontavam o nome de parentes renomados no mundo artístico, caso $\mathrm{o}(\mathrm{a} / \mathrm{x})$ jovem focalizado $(\mathrm{a} / \mathrm{x})$ pela crítica os tivesse entre seus familiares. $\mathrm{O}$ pertencimento a uma linha de sucessão de artistas marcou, portanto, o reconhecimento de muitos(as/xs) jovens, distinguindo-os(as/xs) daqueles(as/xs) que não tinham tal capital.

Em Benjamin Silva, Jovem Pintor, publicado em 24 de abril de 1957, o crítico de arte Mário Pedrosa focaliza o trabalho de Benjamin Silva (1927-) artista cearense a quem tece inúmeros elogios. No texto, o crítico não deixa de mencionar o artista e cenógrafo Tomás Santa Rosa (1909-1956), professor de Silva, que acabara de falecer. Sublinhando a recente orfandade artística de Silva, Pedrosa afirma: "Quando Santa Rosa morreu, Silva era seu aluno. Compreendase assim a orfandade em que ficou o moço do Ceará, ao perder um mestre como o Santa, tão penetrante, tão seguro na observação, tão atento às pequenas coisas decisivas, tão finalmente fraterno e carinhoso para os amigos e discípulos, se não para todos que tiveram a fortuna de com ele lidar [...]”. (PEDROSA, 1957a, p. 08). O aprendizado com Santa Rosa aparece assim como uma espécie de selo de qualidade, atestando a qualidade artística do jovem Benjamin Silva.

Além disso, Mário Pedrosa relacionou os trabalhos do artista às obras de Henry Matisse (1869-1954) e Georges Braque (1882-1963):

[...] A pintura que Benjamin Silva nos apresenta é, ainda, naturalmente elementar. O pintor ainda está em começo. E deixa ver, a cada passo, as origens e influências que pesam, ou pesaram, sobre ele. As de Matisse e de Braque preponderam. Não estamos dizendo isso com reprovação. Verificamos o fato e verificamos com ele que Silva é ainda um pintor em formação. Mas com talento [...] (PEDROSA,1957a, p. 08).

Outro exemplo que merece destaque evidencia como os críticos mobilizam a opinião de outros críticos em seus textos. Em O Jovem Antonio, publicado em 18 de dezembro de 1964, o crítico de arte Harry Laus (1922-1992), apresentava o então jovem artista Antonio Manuel Lima Dias, mais conhecido por Antonio Dias (1944-2018): Há dias, conversando com o pintor Frans Krajcberg,
mostrava-se ele um pouco desiludido com o
movimento das artes plásticas brasileiras, pela
falta de um sentido de renovação, de pesquisa de

11 Os textos publicados no Jornal do Brasil e aqui analisados são: AYALA, Walmir. Um Nôvo Pintor Mineiro. Jornal do Brasil, Caderno B, Rio de Janeiro, p. 02, 25 de junho de 1968; AYALA, Walmir. O Diálogo Difícil. Jornal do Brasil, Caderno B, Rio de Janeiro, p. 02, 19 de agosto de 1973; AYALA, Walmir. O Impacto do Novo. Jornal do Brasil, Caderno B, Rio de Janeiro, p. 02, 22 de agosto de 1973; BESADA, Antonio. Estamos Apresentando Nelson Porto Jovem e Promissor Artista Brasileiro. Jornal do Brasil, $1^{\circ}$ Caderno, p. 03, 02 de dezembro de 1981; COMODO, Roberto. A Fada do Efêmero. Jornal do Brasil, Caderno B, Rio de Janeiro, p. 05, 28 de outubro de 1989; FORTES, Márcia. O Marchand da 'Nova Arte'. Jornal do Brasil, Caderno B, Rio de Janeiro, p. 08, 11 de agosto de 1993; GARCIA, Sérgio. Independência ou Arte. Jornal do Brasil, Caderno B, Rio de Janeiro, p. 22-23, 24 de março de 1991; GOMES, João Paulo. Criando em Bytes e Pixels. Jornal do Brasil, Caderno B, Rio de Janeiro, p. 08, 08 de novembro de 2003.; Jornal do Brasil. Com Genaro de Carvalho a Tapeçaria Começa no Brasil. Jornal do Brasil, Suplemento Dominical, Rio de Janeiro, p. 01, 28 de outubro de 1956; LAUS, Harry. O Jovem Antonio. Jornal do Brasil, Suplemento Dominical, Rio de Janeiro, p. 05, 18 de dezembro de 1964; MARTINS, Ana Cecília; ABREU, Gilberto. Na Fila para Ser Novo. Jornal do Brasil, Caderno B, Rio de Janeiro, p. 01-02, 19 de março de 2000; OLIVEIRA, Bárbara. Em Osso de Peixe, Raras e Estranhas Esculturas. Jornal do Brasil, Caderno B, Rio de Janeiro, p. 06, 30 de outubro de 1984; PASSI, Clara. O Fenômeno das Coisas Mundanas. Jornal do Brasil, Caderno B, Rio de Janeiro, p. 02, 12 de outubro de 2008; PEDROSA, Mário. Benjamin Silva, Jovem Pintor. Jornal do Brasil, Suplemento Dominical, Rio de Janeiro, p. 08, 24 de abril de 1957; PEDROSA, Mário. Krajcberg, Prêmio de nossa Pintura. Jornal do Brasil, Suplemento Dominical, Rio de Janeiro, p. 06, 20 de novembro de 1957; PEDROSA, Mário. Os Projetos de Hélio Oiticica. Jornal do Brasil, Suplemento Dominical, Rio de Janeiro, p. 02, 25 de novembro de 1961; PONTUAL, Jorge. Paulo Laender. Jornal do Brasil, Serviço, Rio de Janeiro, p. 06, 08 de dezembro de 1978; REIS, Paulo. Lista Deixa Dois de Fora. Jornal do Brasil, Caderno B, Rio de Janeiro, p. 06, 10 de fevereiro de 1994. 
novos meios de expressão mais de acordo com o que se realiza em outras partes do mundo. Estava profundamente decepcionado com o nível do Salão Nacional, onde o sentido de imitação prolifera, os artistas se contentando em atingir um grau de virtuosismo que consiga, de certa forma, aproximarse, atingir ou mesmo ultrapassar os mestres e guisas de sua inspiração.

Pouco antes, os mesmos pensamentos nos foram expostos pelo crítico francês Pierre Restany, quando de sua passagem pelo Rio. Vindo de Buenos Aires, pôde comparar os dois centros, em seu sentido artístico, para concluir que o movimento da capital portenha e a obra de alguns argentinos deixa nosso País em estágio inferior.

São duas opiniões respeitáveis as que registramos. Quando apareceu Antonio Dias, com a exposição montada atualmente na Galeria Relêvo, novamente estes dois nomes se aliam para outras conclusões. Restany viu a obra do jovem artista e preparou a apresentação, num atestado da importância que concede a seu trabalho. Krajcberg mostrou-se então mais otimista pois, apesar de reconhecer certas fontes de influência de artistas italianos e espanhóis, também reconheceu a dose de audácia, de independência e sentido de renovação existentes nos quadros de Dias. Falou-nos que se houvessem uns quinze pintores como Antonio Dias poderia ser feito um movimento significativo em nossas artes [...] (LAUS, 1964, p. 05).

A partir de uma visão negativa acerca da produção artística apresentada no antigo Salão Nacional de Belas Artes, Harry Laus menciona as opiniões do pintor Frans Krajcberg (1921-2017) e do francês Pierre Restany (1930-2013) para endossar sua crítica negativa e apresentar o jovem Antonio Dias como uma promessa das artes visuais, que poderia renovar o cenário artístico nacional. Diferentemente de Pedrosa, que se vale do falecido mestre do artista para apresentar Benjamin Silva ao público e também relaciona o trabalho de Silva ao de Braque e Matisse, Harry Laus mobiliza a opinião de especialistas a fim de apoiar sua decisão de escrever um artigo apresentando Antonio Dias como um jovem artista com potencial para alterar os rumos da arte brasileira. Entretanto, de modo semelhante, tanto Pedrosa quanto Laus vinculam os jovens artistas a alguma linhagem artística. Laus recorre aos especialistas e, em seguida, mesmo que indiretamente, vincula Dias aos profissionais das artes que reconhecem nele um talento promissor, ao passo que Pedrosa associa diretamente Silva a seu antigo mestre Santa Rosa e a artistas consagrados como Braque e Matisse.

Em outros artigos analisados, é feito o mesmo tipo de vinculação através da opinião de profissionais legitimados das artes. Em Estamos Apresentando Nelson Porto Jovem e Promissor Artista Brasileiro, publicada em 02 de outubro de 1981, o crítico Antônio Besada afirma: “[...] Críticos como Flavio Aquino, Janez Gartnar, Paschoal Carlos Magno e outros já aplaudiram o jovem artista" (BESADA, 1981, p. 03). Do mesmo modo, no artigo Lista Deixa Dois de Fora, sobre a lista com os nomes de artistas participantes da 22a Bienal Internacional de São Paulo, o crítico Paulo Reis afirma que: “[...] A inclusão de Fernanda Gomes, uma jovem artista pode ser considerada uma artista dos anos 90 - já bastante respeitada por antigas e novas gerações [...]" (REIS, 1994, p. 06). Apesar de não dar os nomes dos profissionais que elogiam e acreditam na obra de Gomes, o artigo dá a ver a aprovação da artista por diversos críticos, corroborando meu argumento.

Outro modo de filiar jovens artistas a uma linhagem artística é indicar influências de artistas consagrados nas obras dos jovens artistas. Constrói-se deste modo uma espécie de diálogo entre $\mathrm{o}(\mathrm{a} / \mathrm{x})$ artista em início de carreira e $\operatorname{algum}(\mathrm{a} / \mathrm{x})$ artista e/ou alguma corrente artística reconhecida e legitimada, fato este que atestaria a qualidade de suas pesquisas estéticas, de suas obras, tornando-os(as/xs) dignos(as/xs) da atenção do público especializado ou não. Os artigos de autoria do crítico de arte e literatura Walmir Ayala (1933-1991) sobre o artista goiano Siron Franco (1947-) são exemplares neste sentido. O Impacto do Novo, publicado em 22 de agosto de 1973, trata da exposição do artista, à época com 26 anos, na então Galeria Intercontinental, em Ipanema no Rio de Janeiro. 
Em O Difícil Diálogo, publicado dias antes, em 18 de agosto, Walmir Ayala recomenda a visita à mostra e comenta o talento de Franco. Em ambos artigos o crítico aponta o que seria a ascendência artística de Siron Franco. No primeiro texto, Ayala diz que: "Premiado na extinta Bienal da Bahia, Siron revela-se um descendente de Bosch, um revisor, em certa fase, da fantasia de Grassmann, acrescentando a tudo isto um toque muito especial (e atual) sobretudo à comunicação e ao difícil diálogo do homem contemporâneo comprimido pela máquina e o desastre [...]" (AYALA,1973a, p. 02). E, no segundo texto mencionado segue a mesma argumentação: “[...] Um Bosch sem assombração, colocando na postura de seus monstros do irracional, as questões mais pertinentes com a realidade existencial do mundo contemporâneo. Descendente artístico de um Bosch ou de um Grassmann, não possui nem a perversidade orgíaca do primeiro nem a natureza de puro sonho do segundo" (AYALA, 1973b, p. 03).

Hieronymus Bosch (1450-1516), pseudônimo do artista renascentista, nascido na Holanda sob o nome Jeroen van Aeken, e o artista, do interior de São Paulo, Marcelo Grassmann (1925-2013), são acionados por Walmir Ayala para mostrar o que seria a ascendência artística de Siron Franco. Não havendo espaço para a repetição mas para a inovação, Franco e suas obras estariam situados no espaço legado por Bosch e Grassmann; sendo Franco responsável por algo novo com qualidade artística, afinal, seria um trabalho inovador e ao mesmo tempo embasado historicamente por sua proximidade com as obras de Bosch e Grassmann.

Os textos de Walmir Ayala e de Mário Pedrosa referidos acima são representativos da vinculação necessária de jovens artistas à historiografia da arte. Roberto Pontual faz o mesmo tipo de apresentação das obras de Paulo Laender: "E se a sua obra mantém evidentes pontos de contato com as de Franz Krajcberg e José Zanine, a proximidade, no caso, não se dá por preguiça ou subserviência de Paulo Laender, e sim porque a ele igualmente interessa um veio de recuperação ecológica, no qual a riqueza expressiva da madeira constitui o ponto de partida" (PONTUAL, 1978, p. 06). Neste sentido, a referência às influências e ascendências parece ser uma das formas de garantir a qualidade dos trabalhos dos jovens artistas apresentados/revelados.

Uma outra forma de apresentação de jovens artistas é a menção a membros de suas famílias conhecidos publicamente pelas suas atividades artísticas. Em 1961, ao focalizar o jovem artista Hélio Oiticica (1937-1980), no artigo Os Projetos de Hélio Oiticica, Mário Pedrosa afirma: "Devese aplaudir, calorosamente, o MAM do Rio de Janeiro, por acolher uma experiência como a desse jovem artista de talento, que é Hélio Oiticica" (PEDROSA,1961, p. 02), se referindo à instalação Cães de Caça, de autoria de Oiticica. Saudando o projeto, o museu e o jovem artista (vinculado a correntes artísticas defendidas por Pedrosa), o crítico diria ainda: "Hélio Oiticica, jovem artista austero, como convém a neto de anarquista ilustre, traz ao nosso museu uma de suas últimas ideias, fruto pessoal do desgarramento coletivo dos concretistas, quando organizaram, sob a liderança Ferreira Gullar-Lygia Clark, o grupo neoconcreto" (PEDROSA, 1961, p. 02).

Embora não se alongue acerca dos laços consanguíneos de Hélio Oiticica, Pedrosa julgou necessário se referir ao avô do artista, naquele momento já falecido, o filólogo e teórico anarquista, José Oiticica (1882-1957). Além disso, Pedrosa aponta outra vinculação de Oiticica, desta vez aos artistas concretistas e neoconcretistas, a quem ele próprio estava relacionado naquele momento. Além dos elogios feitos pelo crítico ao jovem artista, em seu artigo $^{12}$, a produção estética do jovem Oiticica é relacionada a suas heranças familiares e ao grupo de artistas concretistas e neoconcretistas de forma a corroborar a qualidade de suas obras.

Segue ainda outro exemplo da utilização dos laços familiares com a finalidade de demonstrar

12 Não esqueçamos do privilégio que é a um jovem artista ter sua obra divulgada em jornais de grande circulação. 
a qualidade da produção de jovens artistas. Tratase do artigo A Fada do Efêmero, publicado em 28 de outubro de 1989 por Roberto Comodo, sobre a jovem artista, Jac Leirner (1961-). Com 28 anos, a artista constava entre os participantes da $20^{a}$ Bienal de São Paulo e já havia participado da $17^{\mathrm{a}}$ edição do evento em 1983. O artigo avalia as obras da artista e de sua formação em artes, trazendo a opinião de outros artistas sobre o trabalho da jovem, a exemplo de Cildo Meireles (1948), à época um artista já consagrado e Leda Catunda (1961), uma jovem artista como Jac Leirner. Ademais, se refere aos laços de parentesco de Jac Leirner:

[...] Jac não se sente incluída em nenhuma geração, nem mesmo na famosa Geração 80, que nasceu no Rio e englobou artistas paulistas. Ela até teve uma vivência marginal e underground. $O$ fato marcante mesmo é que Jac nasceu numa tradicional família de artistas. Seu pai, um industrial do setor têxtil, dono da confecção Tricolã, é um grande colecionador de art déco e de arte brasileira da década de 50, principalmente dos movimentos concreto e neoconcreto. Sua tia-avó, Felícia Leirner, é escultora; e o pintor Nelson Leirner e a crítica Sheila Leirner são primos em segundo grau de Jac, que ainda tem uma irmã, Betty, poetisa, e uma tia, Janete Musati, artista plástica [...] (COMODO, 1989, p. 05).

Efetivamente, Jac Leirner faz parte de uma família de artistas e esta esfera é evocada como uma instância de legitimação de sua produção, sua formação e sua aptidão para às artes visuais. Entretanto, cabe dizer que, de fato, o pertencimento à família Leirner não garantiria que Jac Leirner se tornasse uma artista, muito menos uma artista com trabalho reconhecido e legitimado pela esfera da arte. Aqui interessa o fato de que os vínculos familiares aparecem nas notícias analisadas, o que indica sua relevância para apresentação de jovens artistas e, igualmente, atestar a qualidade de sua produção artística.

Os quatro modos de argumentação discutidos neste subitem atrelam artistas a algum tipo de linhagem artística que seria responsável por atestar seu talento. É como se sua capacidade de inovar e mesmo a qualidade de seus trabalhos necessitassem de um selo de qualidade, o qual é oferecido pelos críticos de arte e jornalistas culturais a partir da confirmação das origens de tais artistas.

\section{2 - Personalidade e Magia}

Características encaradas como positivas são usualmente utilizadas para definir a personalidade dos indivíduos, como, por exemplo, sinceridade ou dedicação. Estas características aparecem com frequência nos perfis de jovens artistas nos textos de jornal aqui analisados. Ademais, são frequentes as referências a expressões de cunho religioso e a menção a deuses e dádivas, quando se fala do talento dos artistas. Características de personalidade e dons divinos são, deste modo, atrelados aos jovens artistas e às novidades que apresentariam em seus trabalhos.

Em 28 de outubro de 1956, o artigo intitulado Com Genaro de Carvalho a Tapeçaria Começa no Brasil, sem autoria atribuída, ganhava as páginas do Jornal do Brasil. Nele são focalizadas a carreira e a produção do artista Genaro de Carvalho (1926-1971), relatando a saga do artista que, aos 30 anos, conseguiu inventar uma nova técnica para produzir tapeçarias. Além de sublinhar a formação do artista em Paris, Veneza e na Bahia, o artigo traz as opiniões do pintor francês Jean Luçart (1892-1966), do poeta Manuel Bandeira (1886-1968) e do pintor brasileiro José Pancetti (1902-1958) para argumentar que Genaro de Carvalho seria "[...] um dos artistas mais expressivos e de maior significação da nova geração brasileira" (JORNAL DO BRASIL, 1956, p. 01), em frase atribuída a Pancetti. E, em dado momento, o texto se remete à dedicação de Carvalho a sua arte: “[...] O pintor Genaro de Carvalho pioneiro da tapeçaria mural do Brasil não tem encontrado sempre um caminho fácil para realizar sua arte. E muitas vezes quase que o desânimo consegue abater e destruí-lo. [...] Mas ele se dedicara ao seu ofício como quem entra para uma religião [...]" (JORNAL DO BRASIL, 1956, p. 01). A palavra "dedicação" significa 
desprendimento de si próprio em favor de outrem ou de alguma ideia ${ }^{13}$. Ao falar de Genaro de Carvalho como um artista dedicado, qualificase positivamente o artista que, insistindo em sua proposta estética, logrou criar uma técnica favorável à produção de seus trabalhos: "Genaro de Carvalho é uma força que realiza uma arte pessoalíssima cheia de incessante paixão e sobretudo honesta" (JORNAL DO BRASIL, 1956, p. 01).

No mesmo sentido, é possível fazer referência ao artigo Krajcberg, Prêmio de nossa Pintura, publicado por Mário Pedrosa em sua coluna no Jornal do Brasil, em 20 de novembro de 1957. Pedrosa diz que Frans Krajcberg ${ }^{14}$, acabara de receber o prêmio de pintura nacional oferecido pelo júri da $4^{a}$ Bienal Internacional de São Paulo, muito embora fosse de origem polonesa. O crítico não nega o talento de Krajcberg, que estaria “[...] em condições de receber o prêmio. É um jovem e bom pintor em ascensão [...]" (PEDROSA, 1957b, p. 06). Entretanto, discorre sobre o fato de que as pinturas do artista ainda não apresentariam as influências do contexto brasileiro. Dirá o crítico sobre o artista, à ocasião com 36 anos:

\footnotetext{
Trata-se de uma personalidade forte e de um jovem artista de talento e sério. Se ele ficar por aqui, e é o que desejamos, irá sua arte sofrer modificações sugeridas pelo clima espiritual artístico ora predominando nas nossas paragens? Compreendam-me: não quero, não instituo nem peço que Krajcberg se meta a mudar de maneira. Isto seria estultícia de minha parte. Não direi mesmo que ele ficará “melhor” se assim fizer. O que ele deve fazer acima de tudo é ser o que é, é continuar trabalhando com os talentos e a sinceridade que Deus lhe deu (PEDROSA, 1957b, p. 06).
}

Personalidade forte, seriedade, sinceridade e talento. Como no caso de Genaro de Carvalho, os adjetivos atrelados à personalidade do artista são acionados para qualificá-lo. Mas, no caso da crítica a Krajcberg, o aspecto religioso aparece: o talento do artista e a sinceridade expressa em sua obra teriam sido legados por um deus que ungiu o artista e lhe deu o talento indispensável para fazer sua arte.

Os artigos referidos até aqui, para tratar das características de personalidade dos jovens artistas, veiculados nos artigos do Jornal do Brasil são de décadas atrás (de 1950 e 1960). Mas para que $\mathrm{o}(\mathrm{a} / \mathrm{)}$ leitor $(\mathrm{a} / \mathrm{x})$ não pense que se trata de uma tendência histórica e já superada, trazse o artigo Criando em Bytes e Pixels, de João Paulo Gomes, publicado em 08 de novembro de 2003. O texto trata da exposição Olhômetro, com obras do artista Cirilo Quartim, destacando os trabalhos em que o artista utiliza o computador como ferramenta para produção de suas obras:

\section{[...] Deixando o mouse de lado, Cirilo resolveu pegar no pincel para transportar uma das infogravuras para a fachada de $110 \mathrm{~m}^{2}$ do Espaço Cultural, na Avenida W3. Durante os sete dias de trabalho, debaixo de sol e chuva, os amigos apareceram para ajudar, carregando escadas e tintas. $O$ processo foi registrado em vídeo e em fotografias, já disponíveis na página do artista na internet (www.olhometro. cjb.net) [...] (GOMES, 2003, p. 08).}

Interessante, neste caso, é perceber que, embora não mencione características como a dedicação, este aspecto não está de fora: o autor sublinha o esforço do artista que enfrenta intempéries para concluir seu trabalho, valorizando o esforço do artista.

Outro texto que evidencia a evocação de uma dimensão mágica e religiosa é Um Novo Pintor Mineiro, de Walmir Ayala sobre Sebastião Januário, conhecido por Januário (1939-):

13 Verbete do termo dedicação consultado no dicionário Priberam da Língua Portuguesa. Disponível em: <https://www. priberam.pt/dlpo/dedica\%C3\%A7\%C3\%A3o>. Acesso em 17 de janeiro de 2018.

14 Lembrando que Frans Krajcberg, em artigo anteriormente citado, teve sua opinião acerca da produção de Antonio Dias levada em consideração por já ser, em 1964, data daquele artigo, um profissional legitimado pelo universo da arte. 
[...] Januário é um primitivo hoje tão refinado, quanto o era, em seu tempo, o pintor do paleolítico.

Refiro-me a primitivo naquele sentido anterior a tudo o que é história e cultura, e que confeccionava o homem, por uma aptidão de magia, ou supersticiosa sensibilidade, a reproduzir e fascinar. Fascinar: aprisionar e caçar (julgo moral). Januário é autodidata e foi observando coisas do Brasil e do mundo - mas todas as revelações, desde as aulas de Ivan Serpa, até o contato com a obra de Chagall e afrescos da Capela Sistina, foram vertidos numa apaixonada intuição de criação plástica, ao lado de um repúdio à sistemática da teoria. Por isso me referi a um primitivismo. Nele é um comportamento. Sua pessoa é discreta e espantosamente rica de vida interior". (AYALA, 1968, p. 02).

Percebe-se que os críticos recorrem a motivos diversos para apresentar as qualidades artísticas dos jovens aspirantes à carreira, os quais não tem necessariamente a ver com as qualidades intrínsecas ao objeto ou trabalho artístico. A jovem e promissora produção artística é associada com frequência ao parentesco dos jovens com artistas consagrados ou ao aprendizado com mestres reconhecidos no mundo artístico. $\mathrm{O}$ talento dos jovens aparece ainda como uma dádiva concedida por forças mágicas/religiosas/ astrológicas $^{15}$. Neste sentido a novidade que se espera $\operatorname{dos}(\mathrm{as} / \mathrm{xs})$ jovens artistas torna-se natural e inevitável. Os astros, a magia paleolítica e as divindades imprimiriam uma aura sagrada às obras de artistas predestinados(as/xs) ao afazer artístico e fadados a alcançar o sucesso. Neste sentido, vale dizer que os discursos críticos, consciente ou inconscientemente, não evidenciaram a complexa rede de interações, disputas e valores na qual se legitima, reconhece e confere ao jovem artista um novo status no mundo da arte.

\section{3 - O Mercado de Arte e a Arte Jovem}

O fotógrafo Mario Testino, o colecionador de arte Gilberto Chateaubriand, o banqueiro José Olympio Pereira, a socialite Andrea Dellal, o presidente da empresa petrolífera Mariano Marcondes Ferraz e a prestigiosa coleção Cisneros, da Venezuela - a maior coleção de arte da América Latina - já têm os seus. Galerias em Nova York e em Lisboa, assim como a paulistana Casa Triângulo, as cariocas Laura Marsiaj, em Ipanema, e a Arte em Dobro, no Leblon, se apressam em comprar seu passe. $\mathrm{O}$ alvo de apostas desde que despontou em coletivas organizadas no Paço Imperial e no MAM em 2002 é o niteroiense Felipe Barbosa, de 30 anos. Prestes a enviar trabalhos para a Latin American Art Fair, em Nova York, e recém-chegado do Japão, onde participou de uma coletiva, Barbosa expõe 10 de seus mais recentes objetos a partir de quarta-feira, dia 16, na mostra Condomínio, na Arte em Dobro [...] (PASSI, 2008, p. 02).

O Marchand da 'Nova Arte' - Jay Jopling circula por galerias brasileiras e elogia Zerbini e Barrão (FORTES, 1993, p. 08).

Porto Alegre - Carioca, radicado em Florianópolis, 33 anos, ex-publicitário, o artista plástico Silvino Goulart utiliza matéria-prima no mínimo estranha para montar suas peças: ossos de peixes, principalmente garopa, melro, boto e até leão marinho. Foi por utilizar esse material e pela criatividade das peças, que Silvino chamou a atenção de um marchand brasileiro radicado na Itália, que promete apresentá-lo à Europa e também aos brasileiros [...] (OLIVEIRA, 1984, p. 06).

Nas críticas veiculadas no Jornal do Brasil, uma outra característica merece atenção. Ao apresentar jovens artistas ao público explicitase, por vezes, sua relação com colecionadores e galeristas. Os textos que fazem referência ao mercado de arte aparecem com mais frequência 
nas últimas décadas do século passado. Além das qualidades estéticas, os trabalhos dos(as/ xs) jovens artistas tornam-se um investimento oportuno a galeristas e colecionadores. Se para jovens artistas é relevante ter trabalhos em coleções renomadas, uma vez que atraem a atenção de outros compradores bem como de instituições, a palavra de colecionadores e galeristas sobre $\mathrm{um}(\mathrm{a} / \mathrm{x})$ artista e seus trabalhos vale para o mercado de arte, sobretudo, na esfera da arte contemporânea, na qual o preço depende de uma negociação entre o valor do trabalho artístico e o valor de mercado que reúne os personagens envolvidos no mundo da arte (MOULIN, 2007).

Os fragmentos textuais que abrem esse subitem corroboram o argumento acima. $\mathrm{Na}$ matéria de 1984 de Bárbara Oliveira, Em Osso de Peixe, Raras e Estranhas Esculturas, que trata das obras do artista Silvino Goulart, é possível notar já no primeiro parágrafo o interesse que a obra de Goulart causou no marchand e antiquário italiano José Laurentino Neto, indicando o interesse de mercado pelos trabalhos do artista; já na reportagem de 2008, O Fenômeno das Coisas Mundanas - Felipe Barbosa, destaque da nova geração, atrai a atenção de colecionadores ilustres, de Clara Passi, o parágrafo que abre o texto, citado acima, menciona o nome seis colecionadores (Mario Testino, Gilberto Chateaubriand, José Olympio Pereira, Andrea Dellal, Mariano Marcondes Filho e a coleção Cisneros) que possuíam os trabalhos do artista Felipe Barbosa. Neste caso, assim como no de Silvino Goulart, a relação com o mercado é a porta de entrada do texto para tratar da qualidade das obras do jovem artista; a terceira reportagem, datada de 1993, que conta com uma entrevista realizada por Marcia Fortes com o então jovem galerista, Jay Jopling, dono da White Cube, possui um subtítulo que atraí atenção para dois jovens artistas brasileiros daquele momento: Jay Jopling circula por galerias brasileiras e elogia Zerbini e Barrão. Isto porquê na entrevista, o galerista, já renomado à época, defende que as produções de Zerbini e Barrão possuíam qualidades merecedoras da atenção do universo da arte ${ }^{16}$.

$\mathrm{Na}$ Fila para Ser Novo, reportagem de Ana Cecília Martins e Gilberto Abreu, datada de março de 2000, discorre a saga de jovens artistas por reconhecimento no campo da arte. Um dos subitens da reportagem: A Nova Geração Veio dos Salões - Revelados em seleções competitivas hoje podem valer até $R \$ 25$ mil, trata do sucesso de artistas revelados(as/xs) em salões de arte, indicando como marco do sucesso o valor de suas obras no mercado de arte:

\section{[...] Na opinião de artistas que já passaram por salões e hoje são reconhecidos no circuito, a experiência é fundamental para dar uma vivência da obra de arte fora do ambiente em que foi produzida e uma dimensão de seu impacto junto ao observador, seja ele o público, o crítico ou, por sorte, o colecionador. O quesito prêmio é um capítulo à parte: com ele, o artista novo pode não apenas dar prosseguimento às pesquisas como ter uma primeira noção do quanto vale a sua obra.}

Walter Goldfarb já pintava há cinco anos quando entrou pela primeira vez nos extintos salões Macunaíma e Carioca. "Foi quando percebi que minha obra já estava no caminho que intencionava", lembra o artista, ex-Novíssimos em 1997. Ter participado dos salões deu a ele a visibilidade que precisava. "O Thomas me conheceu por causa de um salão e hoje trabalhamos juntos", disse o artista, cuja obra hoje custa em torno de R\$ 25 mil. [...] (MARTINS e ABREU, 2000, p. 02).

Discutindo, portanto, a importância de mostras que apresentam artistas em início de carreira, a reportagem destacada acima confirma a percepção de que jovens artistas podem ser um investimento oportuno a galeristas e

16 A jornalista responsável pela entrevista com o dono da White Cube é, atualmente, sócia de uma das principais galerias do Brasil, a Fortes D’Aloia \& Gabriel, com sedes no Rio de Janeiro e em São Paulo. Barrão (1959-) e Luiz Zerbini (1959-), artistas mencionados na entrevista que realizou com Jay Jopling, presentemente fazem parte do grupo de artistas representados por sua galeria. 
colecionadores. Antes desconhecidos, suas obras podem, entretanto, alcançar altas cifras.

Independência ou Arte - A briga do pintor Hilton Berredo com seu marchand agita as galerias, anunciava o Jornal do Brasil em 24 de março de 1991, em matéria de Sérgio Garcia. Hilton Berredo (1954-), aos 37 anos, trabalhara ao longo de seis anos com o galerista Thomas Cohn, dono de uma das principais galerias de arte do Rio de Janeiro entre os anos de 1983 e 1997, a Thomas Cohn Arte Contemporânea. A reportagem de duas páginas trata do caso Berredo x Cohn, dando um panorama do cenário do mercado de arte em início dos anos de 1990, ao tratar dos acordos entre artistas e galeristas:

Dias atrás, o mercado de arte contemporânea saiu do marasmo em que foi jogado desde a implantação do Plano Collor, em março do ano passado. A agitação não passou pelas galerias, que continuam desertas. O que esquentou o panorama artístico do Rio foi o anúncio da separação de Hilton Berredo do marchand Thomas Cohn. "As nossas divergências eram muitas", diz o pintor. Um dos expoentes da Geração 80, um grupo de novos pintores e escultores que reúne gente do quilate de Daniel Senise e Luiz Pizarro, Berredo há tempos vinha se digladiando com a forma da política de internacionalização da arte brasileira promovida pelo marchand. "O Cohn fica exportando a produção nacional, mas o que aparentemente parece positivo acaba sendo ruim, porque o artista perde o controle do valor de sua obra”, diz Berredo, que agora pretende expor suas obras em galerias de menor expressão e escapar ao cabresto dos marchands. (GARCIA, 1991, p. 22).

Nota-se que o mercado de arte aparece ora como salvador, ora como malfeitor. Se, de um lado, garante visibilidade a artistas e a comercialização de suas obras, de outro, pode se tornar especulativo e nocivo aos artistas, como no caso da matéria acerca da saída de Hilton Berredo de sua antiga galeria. Mas, fato é que a relação artistas-mercado também surge nas matérias de jornal a fim de tratar dos(as/xs) jovens artistas.

\section{Considerações Finais: o Interesse}

\section{Institucional pela Novidade e sua permanência?}

Tomar como objeto as críticas de arte e notícias de jornalismo cultural publicadas no Jornal do Brasil entre os anos de 1950 e 2000 permite a percepção de como o teor da crítica foi alterado ao longo dos anos. Se na década de 1950 era frequente encontrar textos de teor mais militante (TRINDADE, 2008), a passagem para os anos 2000 permite a compreensão de que a crítica de arte anteriormente publicada no periódico mudou de teor, estando mais próxima do, acima referido, jornalismo cultural. Mas guardadas as diferenças contextuais e de conteúdo dos textos, as matérias têm algo em comum: a apresentação de jovens artistas ao público, contribuindo para a construção de suas carreiras. Os(as/xs) jovens artistas aparecem como consistentes, promissores(as/xs) e inovadores(as/xs); como artistas que poderiam mudar os rumos das artes visuais no contexto brasileiro, e, ainda, ser um bom investimento para amantes ou especuladores das artes.

Retomando apenas os títulos de algumas das matérias trazidas acima, fica patente o fascínio pelo novo em Benjamin Silva, Jovem Pintor, de Mário Pedrosa; O Jovem Antônio, de Harry Laus; Um Nôvo Pintor Mineiro, de Walmir Ayala; $O$ Impacto do Novo, igualmente de Walmir Ayala; O Marchand da 'Nova Arte', de Márcia Fortes; e, Na Fila para Ser Novo, de Ana Cecília Martins e Gilberto Abreu. Um fato se torna claro: os(as/ xs) jovens artistas são notícia - e isto, não é novo. Como discutido acima, aparecem como objeto dos textos analisados de diferentes maneiras: 1) mostrando seus perfis ao público mediante suas relações familiares ou sua ligação a artistas consagrados e, ainda, a galeristas, colecionadores e professores; 2) recorrendo a forças de caráter mágico, religioso e/ou astrológico para explicar seu talento; ou ainda, 3) por meio de reportagens que tratam artistas em carreiras iniciais como bom investimento.

É possível afirmar que os(as/xs) jovens artistas corporificam o espectro da novidade que sacia um desejo institucional pela novidade. Isto porque: a) ser responsável pela revelação e apoio da carreira 
de um $(\mathrm{a} / \mathrm{x})$ artista "talentoso" que poderá renovar as práticas artísticas, garante as prerrogativas dos críticos, curadores, diretores de museus, galeristas e colecionadores, os quais, em seu âmbito de atuação, são responsáveis por apoiar e incentivar artistas e linguagens estéticas; b) a revelação e apoio de carreiras artísticas promissoras pode, eventualmente, assegurar um lugar na história da arte aos(às/xs) profissionais responsáveis por tais descobertas (sejam curadores(as/ $\mathrm{xs}), \quad$ críticos(as/xs), artistas renomados(as/ $\mathrm{xs}$ ), colecionadores(as/xs), jornalistas culturais entre outros). Exemplo, neste sentido, é Mário Pedrosa, que dentre suas inúmeras atividades, destacou-se pelo seu envolvimento com a arte concreta, ficando associado à história da arte brasileira pelo incentivo e apoio dado aos jovens artistas concretistas e neoconcretistas ${ }^{17}$; e, c) no mercado de arte, o valor das obras de jovens artistas não é tão alto (ou espera-se que não seja) quanto o dos trabalhos de artistas consagrados(as/xs), representando eles(as/xs), assim, um bom investimento. Aos interessados em lucro financeiro, os trabalhos de artistas jovens podem se valorizar e atingir altas cifras; e aos interessados em prestígio e em um lugar na história da arte, seus nomes podem ser atrelados aos(às/xs) artistas de sua predileção, ou mesmo a movimentos estéticos.

Deste modo, a noção de mudança que permeia tais motivações e interações na esfera da arte parece atrelada ao que seriam novidades e renovações necessárias ao funcionamento deste microcosmos social. Isso não quer dizer que não haja regularidade e conservação de prática artísticas. É importante notar que:

[...] As duas forças, a da mudança e a da conservação, estão sempre a atrair indivíduos e coletividades que, indo de um lado para o outro, procuram o melhor juízo para decidir que caminho escolher. Nem sempre chegam a esse julgamento tão decisivo. A complexidade da vida social lhes impõe ambivalências e ambiguidades - deseja-se mudar em algumas esferas da vida e anseia-se pela permanência de outras. As visões do passado e as imagens do futuro são, entretanto, acima de tudo, formas de controle político e social da vida das coletividades da ordem social (VILLAS BÔAS, 2006, p. 16-17).

Em Mudança Provocada - Passado e Futuro no Pensamento Sociológico Brasileiro, Glaucia Villas Bôas analisa como a mudança e a conservação da estrutural social foram debatidas e compreendidas por diferentes pensadores brasileiros, como Gilberto Freyre (1900-1987) e Florestan Fernandes (1920-1995), permitindo o entendimento de que o jogo entre permanência e mudança é, de fato, uma constante da vida social e que há diferentes maneiras de compreender como se conservam ou alteram regras e costumes sociais.

A partir deste entendimento, e analisando o que seria uma tradição do novo (ROSENBERG, 2004), torna-se evidente que há uma permanência renovada da arte e dos artistas. Se os críticos de arte perderam espaço no Brasil (TRINDADE, 2008), os curadores de exposições angariaram um lugar importante na estrutura de legitimação de artistas e obras (MARCONDES, 2014). Dentre os(as/xs) jovens artistas é possível que alguns(mas/mxs) personagens ganhem mais força substituindo outros(as/xs) que até então tinham a prerrogativa de divulgar, legitimar e reconhecer artistas e seus produtos estéticos. Ao que parece, existiram, existem e, talvez, existam sempre personagens que atuarão na seleção de seus sucessores e de movimentos estéticos aos quais aderem. Se há permanências, há também mudanças.

Ao tratar de uma tradição do novo na arte, focaliza-se o constante e permanente desejo por novidades que alterem as linguagens estéticas

17 Para mais informações sobre a trajetória de Pedrosa e sua aproximação com a arte concreta, consultar o documentário Formas do Afeto: Um Filme sobre Mário Pedrosa, 2010, de Glaucia Villas Bôas e Nina Galanternick. Além do capítulo de livro: O Ateliê do Engenho de Dentro como Espaço de Conversão (1946-1951). Arte Concreta e Modernismo no Rio de Janeiro (VILLAS BÔAS, 2008). 
a serem postas em prática no mundo da arte, sendo estas reconhecidas e legitimadas pelos profissionais das artes e pelo público em geral. $\mathrm{O}$ desejo pelo novo é, então, compreendido como algo que faz parte da estrutura de funcionamento do universo da arte, o que não significa que as novidades alterem as hierarquias e o papel dos profissionais, que criam, mantêm e regulam as regras da arte. A perda de espaço pelos críticos não se deve às novidades estéticas, mas às mudanças tecnológicas e políticas que ocorreram na imprensa, pois a crítica continua sendo feita, só que em outros suportes e formatos. Hoje como ontem, os artistas se posicionam criticamente em relação a atitudes que julgam tirânicas, seja por parte de curadores(as/xs) e críticos(as/xs), seja por parte de galeristas e colecionadores(as/xs), que atuam no mercado de arte. Porém, mantém relações com todos eles. De fato, há mudanças, mas há permanências.

$\mathrm{O}$ chamado interesse institucional pela novidade, portanto, parece estar atrelado a forças de permanência, que estariam ligadas à instituições e profissionais legitimadores das artes, como curadores(as/xs), críticos(as/xs), galeristas e colecionadores(as/xs). Enquanto isso, a potência de mudança estaria atrelada aos(às/xs) artistas e suas obras/práticas artísticas. Tal mudança transformadora alcançaria espaço e visibilidade a partir dos interesses dos demais profissionais e instituições artísticas. A constância parece ser de um movimento de mudança e renovação, que para obter espaço e se efetivar como regra do universo da arte, precisariam ser incorporadas e transmutadas em novas regras do universo artístico, tornandose, de alguma forma, forças de permanência. O esquema: mudança $<->$ permanência $<->$ mudança $<\longrightarrow$ permanência, e, assim por diante, parece, por conseguinte, ser uma das chaves de funcionamento do universo da arte.

\section{Referências Bibliográficas}

AMARAL. Aracy. O Curador como Estrela. In: AMARAL, Aracy. Textos do Trópico de
Capricórnio - Artigos e Ensaios (1980-2005): Bienais e artistas contemporâneos no Brasil. São Paulo: Ed. 34, v. 3, 2006.

BECKER, Howard S. Art worlds. Berkeley: University of California Press, [1982] 2008.

BOURDIEU, Pierre. As Regras da Arte. São Paulo: Companhia das Letras, 1996. Razões Práticas - Sobre a Teoria da Ação. Campinas/SP: Papirus Editora, 2011.

CASTELLS, Manuel. A Sociedade em Rede. São Paulo: Paz e Terra, 1999.

EAGLETON, Terry. A função da Crítica. São Paulo: Martins Fontes, 1991.

ELIAS, Norbert. Mozart - Sociologia de um Gênio. Rio de Janeiro: Jorge Zahar Editor, 1994.

GELDZAHLER, Henry. O Público de Arte e o Crítico. In: BATTCOCOK, Gregory (Org.). A Nova Arte. São Paulo: Perspectiva, 1975.

HABERMAS, Jürgen. Estruturas Sociais da Esfera Pública. In: HABERMAS, Jürgen. Mudança Estrutural da Esfera Pública - investigações quanto a uma categoria da sociedade burguesa. Rio de Janeiro: Tempo Presente, 1984.

MOULIN, Raymonde. O Mercado da Arte: Mundialização e Novas Tecnologias. Porto Alegre: Zouk, 2007.

ROSENBERG, Harold. Objeto Ansioso. São Paulo: Cosac \& Naify, 2004.

VILLAS BÔAS, Glaucia. O ateliê do Engenho de Dentro como espaço de conversão (1946- 1951). Arte concreta e modernismo no Rio de Janeiro. In: BOTELHO, A., BASTOS, E.R., VILLAS BÔAS, G. (orgs). O Moderno em Questão: a década de 1950 no Brasil. Rio de Janeiro: Topbooks, 2008. Mudança Provocada - Passado e Futuro 
no Pensamento Sociológico Brasileiro. Rio de Janeiro: FGV, 2006.

\section{Dissertações de Mestrado e Tese de Doutorado:}

\author{
MARCONDES, Guilherme. Arte, Crítica
}

e Curadoria: Diálogos sobre Autoridade e

Legitimidade. Dissertação (Mestrado em Sociologia) - Programa de Pós-Graduação em Sociologia e Antropologia UFRJ, Rio de Janeiro, 2014.

Arte e Consagração: Os Jovens artistas

da Arte Contemporânea. Tese (Doutorado em Sociologia) - Programa de Pós-Graduação em Sociologia e Antropologia UFRJ, Rio de Janeiro, 2018.

TRINDADE, Mauro. Transformação: A Crítica de Artes Visuais nos Jornais Cariocas nos anos 90. Dissertação (Mestrado), Programa de PósGraduação em Artes Visuais da Escola de Belas Artes da Universidade Federal do Rio de Janeiro, Rio de janeiro, 2008.

\section{Referências de Periódicos:}

AYALA, Walmir. Um Nôvo Pintor Mineiro. Jornal do Brasil, Caderno B, Rio de Janeiro, p. 02, 25 de junho de 1968. Acesso através da Hemeroteca Digital da Biblioteca Nacional (<http://bndigital. bn.gov.br/hemeroteca-digital/ >).

O Diálogo Difícil. Jornal do Brasil, Caderno B, Rio de Janeiro, p. 02, 19 de agosto de 1973a. Acesso através da Hemeroteca Digital da Biblioteca Nacional (<http://bndigital.bn.gov.br/ hemeroteca-digital/ $>$ ).

O Impacto do Novo. Jornal do Brasil, Caderno B, Rio de Janeiro, p. 02, 22 de agosto de 1973b. Acesso através da Hemeroteca Digital da Biblioteca Nacional (<http://bndigital.bn.gov.br/ hemeroteca-digital/ $>$ ).
BESADA, Antonio. Estamos Apresentando Nelson Porto Jovem e Promissor Artista Brasileiro. Jornal do Brasil, $1^{\circ}$ Caderno, p. 03, 02 de dezembro de 1981. Acesso através da Hemeroteca Digital da Biblioteca Nacional (<http://bndigital.bn.gov.br/hemeroteca-digital/ $>)$.

COMODO, Roberto. A Fada do Efêmero. Jornal do Brasil, Caderno B, Rio de Janeiro, p. 05, 28 de outubro de 1989. Acesso através da Hemeroteca Digital da Biblioteca Nacional (<http://bndigital. bn.gov.br/hemeroteca-digital/ >).

FORTES, Márcia. O Marchand da 'Nova Arte'. Jornal do Brasil, Caderno B, Rio de Janeiro, p. 08, 11 de agosto de 1993. Acesso através da Hemeroteca Digital da Biblioteca Nacional (<http://bndigital.bn.gov.br/hemeroteca-digital/ $>)$.

GARCIA, Sérgio. Independência ou Arte. Jornal do Brasil, Caderno B, Rio de Janeiro, p. 22-23, 24 de março de 1991. Acesso através da Hemeroteca Digital da Biblioteca Nacional (<http://bndigital. bn.gov.br/hemeroteca-digital/ $>$ ).

GOMES, João Paulo. Criando em Bytes e Pixels. Jornal do Brasil, Caderno B, Rio de Janeiro, p. 08, 08 de novembro de 2003. Acesso através da Hemeroteca Digital da Biblioteca Nacional (<http://bndigital.bn.gov.br/hemeroteca-digital/ $>)$.

HEINICH, Nathalie. Práticas da Arte Contemporânea: Uma Abordagem Pragmática a um Novo Paradigma Artístico. Revista Sociologia \& Antropologia, Rio de Janeiro, v. 04, n.02, p. 373 390, 2014.

JORNAL DO BRASIL. Com Genaro de Carvalho a Tapeçaria Começa no Brasil. Jornal do Brasil, Suplemento Dominical, Rio de Janeiro, p. 01, 28 de outubro de 1956. Acesso através da Hemeroteca Digital da Biblioteca Nacional (<http://bndigital. bn.gov.br/hemeroteca-digital/ >). 
LAUS, Harry. O Jovem Antonio. Jornal do Brasil, Suplemento Dominical, Rio de Janeiro, p. 05, 18 de dezembro de 1964. Acesso através da Hemeroteca Digital da Biblioteca Nacional (<http://bndigital.bn.gov.br/hemeroteca-digital/ $>)$.

MARTINS, Ana Cecília; ABREU, Gilberto. Na Fila para Ser Novo. Jornal do Brasil, Caderno B, Rio de Janeiro, p. 01-02, 19 de março de 2000. Acesso através da Hemeroteca Digital da Biblioteca Nacional (<http://bndigital.bn.gov.br/ hemeroteca-digital/ $>$ ).

OGUIBE, Olu. O Fardo da Curadoria. Concinnitas - Revista do Instituto de Artes da UERJ. Rio de Janeiro, vol. 5, nº 6, pp. 6-17, jul. 2004.

OLIVEIRA, Bárbara. Em Osso de Peixe, Raras e Estranhas Esculturas. Jornal do Brasil, Caderno B, Rio de Janeiro, p. 06, 30 de outubro de 1984. Acesso através da Hemeroteca Digital da Biblioteca Nacional (<http://bndigital.bn.gov.br/ hemeroteca-digital/ $>$ ).

PASSI, Clara. O Fenômeno das Coisas Mundanas. Jornal do Brasil, Caderno B, Rio de Janeiro, p. 02, 12 de outubro de 2008. Acesso através da Hemeroteca Digital da Biblioteca Nacional (<http://bndigital.bn.gov.br/hemeroteca-digital/ $>)$.

PEDROSA, Mário. Benjamin Silva, Jovem Pintor. Jornal do Brasil, Suplemento Dominical, Rio de Janeiro, p. 08, 24 de abril de 1957a. Acesso através da Hemeroteca Digital da Biblioteca Nacional (<http://bndigital.bn.gov.br/hemeroteca-digital/ $>)$.

. Krajcberg, Prêmio de nossa Pintura. Jornal do Brasil, Suplemento Dominical, Rio de Janeiro, p. 06, 20 de novembro de 1957b. Acesso através da Hemeroteca Digital da Biblioteca Nacional (<http://bndigital.bn.gov.br/ hemeroteca-digital/ $>$ ).
Brasil, Suplemento Dominical, Rio de Janeiro, p. 02, 25 de novembro de 1961. Acesso através da Hemeroteca Digital da Biblioteca Nacional (<http://bndigital.bn.gov.br/hemeroteca-digital/ $>)$.

PONTUAL, Jorge. Paulo Laender. Jornal do Brasil, Serviço, Rio de Janeiro, p. 06, 08 de dezembro de 1978. Acesso através da Hemeroteca Digital da Biblioteca Nacional (<http://bndigital.bn.gov.br/ hemeroteca-digital/ $>)$.

REIS, Paulo. Lista Deixa Dois de Fora. Jornal do Brasil, Caderno B, Rio de Janeiro, p. 06, 10 de fevereiro de 1994. Acesso através da Hemeroteca Digital da Biblioteca Nacional (<http://bndigital. bn.gov.br/hemeroteca-digital/ >).

\section{Imagem em Movimento:}

Formas do Afeto: Um Filme Sobre Mário Pedrosa. Direção: Glaucia Kruse Villas Bôas e Nina Galanternick, 2010. 